\title{
Low literacy: a hidden problem in family planning clinics
}

\author{
Jeanne Rutherford, Ruth Holman, John MacDonald, Avril Taylor, Dominic Jarrett, Alison Bigrigg
}

\begin{abstract}
Objectives Low literacy is highly prevalent among UK adults. This study assessed functional health literacy among family planning clinic clients and whether this was associated with sexual health knowledge and behaviours. It also assessed the readability of patient leaflets.

Methods 505 female family planning clinic attendees aged 16-35 years were interviewed about their sexual behaviour and knowledge. Their reading age was assessed using a validated test (REALM). The readability of leaflets on contraception supplied to clinic users was measured.

Results All respondents had a reading age of 12 years and above, 221 (43.8\%) between 12 and 14 years and $284(56.2 \%)$ greater than 14 years. Those in the lower literacy group were significantly more likely to have been aged under 16 years at time of first sexual intercourse, and significantly less likely to know the most fertile time of the menstrual cycle, to identify sexually transmitted infections and to know that sexual infections can be transmitted through oral and anal sex. The reading age of information leaflets in the clinics ranged from 11 to 17 years. Thus, clients with a reading level of 12-14 years would have difficulty in understanding some of the leaflets.

Conclusions Functional health literacy is related to sexual behaviour and knowledge. Written information should be prepared with this in mind and other routes of communication considered.
\end{abstract}

J Fam Plann Reprod Health Care 2006; 32(4): 235-240 (Accepted 13 June 2006)

\section{Key message points \\ - Low literacy is associated with less knowledge about sexual health and riskier sexual behaviour. \\ - Many family planning clinic clients have low literacy skills. \\ - Many of the leaflets available in family planning clinics will not be fully understood by clients.}

Institute for Applied Social and Health Research and School of Social Sciences, University of Paisley, Paisley, UK

Jeanne Rutherford, MA, Research Assistant

Avril Taylor, MA, PhD, Professor/Director and Associate Dean

(Research and Commercialisation)

Department of Sexual Health, Ayrshire Central Hospital, NHS Ayrshire and Arran, Irvine, UK

Ruth Holman, MSc, MFFP, Consultan

Division of Psychology, School of Social Sciences, University of Paisley, Paisley, UK

John MacDonald, MSc, PhD, Professor

Learning Disability Service, NHS Ayrshire and Arran, Arrol Park Resource Centre, Ayr, UK

Dominic Jarrett, BA, MSc, Research and Information Officer

The Sandyford Initiative, Glasgow, UK

Alison Bigrigg, FFFP, FRCOG, Director

Correspondence to: Dr Ruth Holman, Department of Sexual Health, Ayrshire Central Hospital, Irvine KA12 8SS, UK.

E-mail: ruth.holman@aapct.scot.nhs.uk

\section{Introduction}

Literacy can be situation specific: what is adequate for a person's daily routine may not be sufficient for other situations, for example, engaging with health services where one has to read, understand and make use of signposts to departments, medicine labels, appointment cards, consent forms and information leaflets. ${ }^{1}$ Functional health literacy is the ability to apply reading, writing and numeracy skills ('basic skills') to health-related situations, at a level adequate to allow a person to participate in their own health care. ${ }^{1}$ Low literacy is a common but hidden problem independently associated with poorer health outcomes. ${ }^{2}$ Practitioners in reproductive health care place great emphasis on individuals taking responsibility for their own well-being, and participating in health promoting behaviours. ${ }^{3}$ Current strategies to engage people in these behaviours rely heavily on the use of written information with high reading levels, thus disadvantaging low literate individuals. ${ }^{3}$ Low functional health literacy creates barriers to fully understanding one's health/illness, making informed choices and adhering to treatment regimes. 1,3

Little is known of the effects of low literacy skills on engagement with family planning services, use of contraception and clinical outcomes, ${ }^{4}$ but adults with poor basic skills are more likely to have children at an early age and to have more children. ${ }^{5}$ The prevalence of literacy problems in the client population of UK family planning clinics is unknown.

This study aimed to assess functional health literacy among family planning clinic clients and whether this was associated with sexual health knowledge and behaviours. The study also assessed the clinic literature available to these clients in terms of its readability.

\section{Methods}

Sample size

Based on the total numbers of women attending the clinics each year, the size of sample needed to calculate the true prevalence of low literacy in the community with a $3 \%$ percentage error of estimation of magnitude was 350 .

\section{Recruitment}

Recruitment for the study took place in National Health Service (NHS) family planning clinics in Greater Glasgow and Ayrshire and Arran Health Board areas. The original aim of the study was to recruit both male and female clients aged 16 years and over. However, pilot work suggested that the recruitment of a proportionate sample of male clients would take longer than the period of fieldwork would allow. Although studies such as the National Survey of Sexual Attitudes and Lifestyles (NATSAL) ${ }^{6}$ indicate that both men and women take responsibility for contraception, women need to make greater use of clinical services to access their contraceptive methods and so are an easier group to recruit. Furthermore, women would need greater literacy skills to achieve this access, negotiate the contraceptive choices available and, with some methods, use them correctly.

Women aged 16 years and over, whose first language was English, were approached in the clinic waiting room and asked to consent to participate in the study. They were 


\section{ARTICLE}

Table 1 School grade systems in Scotland and the USA

\begin{tabular}{lll}
\hline Age (years) & School year (Scotland) & School grade (USA) \\
\hline $4-5$ & Primary 1 & Kindergarten \\
$5-6$ & Primary 2 & 1st Grade \\
$6-7$ & Primary 3 & 2nd Grade \\
$7-8$ & Primary 4 & 3rd Grade \\
$8-9$ & Primary 5 & 4th Grade \\
$9-10$ & Primary 6 & 5th Grade \\
$10-11$ & Primary 7 & 6th Grade \\
$11-12$ & 1st Year High School & 7th Grade \\
$12-13$ & 2nd Year High School & 8th Grade \\
$13-14$ & 3rd Year High School & 9th Grade \\
$14-15$ & 4th Year High School & 10th Grade \\
$15-16$ & 5th Year High School & 11th Grade \\
$16-17$ & 6th Year High School & 12th Grade \\
\hline
\end{tabular}

given an information sheet outlining the study and given an opportunity to ask questions. Within the Ayrshire and Arran clinic, clients were also asked to sign a consent form, a condition of the local ethics committee not imposed by the Glasgow local ethics committee. Those who consented to the study were interviewed using a structured questionnaire in a private room. The questionnaire asked participants questions relating to their demographics, sexual health behaviour and knowledge. Respondents' health literacy levels were then assessed using a recognised instrument, Rapid Estimate of Adult Literacy in Medicine (REALM). ${ }^{7}$ The time taken to complete both the interview and the questionnaire was approximately 15 minutes. Information leaflets about the study containing contact details for local adult education literacy teams were available to all participants.

\section{REALM}

REALM $^{7}$ is a screening instrument used to assess an adult patient's ability to read common medical words and lay terms for body parts and illnesses. It is a 66-item word recognition test that assigns reading age estimates based on the total score. One mark is given for each correctly pronounced word; the REALM score is the sum of the correctly pronounced words.

\section{Assessment of leaflet readability}

All currently available leaflets used within the participating family planning services were evaluated using the SMOG Readability Formula ${ }^{8}$ to assess their reading level. This formula is used to determine the literacy level required to understand written material. Reading ability is often expressed in terms of reading age in the UK and as a grade level in the USA. This is based on the expected reading ability of the average person of that age or school year. The USA grade system and their Scottish equivalents are shown in Table 1 .
The leaflets were also assessed using the FleschKincaid Readability Formula, ${ }^{9}$ a programme that is built into the Microsoft Word ${ }^{\mathrm{TM}}$ word processing package. This is similar to SMOG scoring in that it uses grade level to report the reading level. The contents of all the leaflets were manually entered into Word and assessed.

\section{Data analysis}

The data from the questionnaire and REALM test were entered into a Statistical Package for the Social Sciences (SPSS) database (SPSS Inc., Chicago, IL, USA) and the differences between the two groups were analysed using $t$-test and Chi-square tests as appropriate. The Mann-Whitney test was used to analyse the ordinal level data from the Likert scale where participants judged the helpfulness of information leaflets.

\section{Results}

\section{Sample}

All the participants were female and white. A total of 590 family planning clinic attendees were approached to take part in the study. Eighty-five people declined to participate in the study. The 505 women who agreed to participate were aged 16-35 (mean, 23.1) years. There is a small but statistically significant difference between the ages of the people in the low and high literacy groups: low literacy group $(n=221)$ mean $=22.43$ years, standard deviation $(\mathrm{SD})=4.84$; high literacy group $(n=284)$ mean 23.61 years, $\mathrm{SD}=5.22[t=-2.50$, degrees of freedom $(\mathrm{df})=503$, $p<0.01]$.

Each woman completed both the questionnaire and REALM test. Sixty-nine (13.7\%) participants had no qualifications. The remainder $(n=436,86.3 \%)$ possessed qualifications ranging from SCE Standard/'O' grades (exams taken at age 16 years) to university degree level. Most of the participants $(495,98.0 \%)$ had been sexually active and most $(494,97.8 \%)$ had used some form of contraception in the previous 6 months.

\section{Functional health literacy}

Scores on the REALM ranged from 47 to 66 with a mean score of $61.3(\mathrm{SD}=4.62)$, corresponding to a reading age greater than 14 years. The REALM results are shown in Table 2.

\section{Literacy levels and sexual health knowledge and behaviours}

Participants were divided into two groups according to their level of literacy. In accordance with previous use of the REALM the cut-off point was set at 60 and below. The low literacy group $(n=221)$ had a mean REALM score of $56.76(\mathrm{SD}=3.03)$ and the high literacy group $(n=284)$ a

Table 2 Participants' REALM scores with corresponding reading age $e^{10}$

\begin{tabular}{|c|c|c|c|c|}
\hline REALM score & Number $(\%)$ with this score & USA school grade range & Reading age (years) & Comprehension \\
\hline $0-18$ & $0(0 \%)$ & 3rd Grade and below & $\leq 8$ & $\begin{array}{l}\text { Will not be able to read most low } \\
\text { literacy materials. Will need repeated } \\
\text { oral instructions, materials composed } \\
\text { primarily of instructions, or audio/videotapes }\end{array}$ \\
\hline $19-44$ & $0(0 \%)$ & 4th to 6th Grade & $9-11$ & $\begin{array}{l}\text { Will need low literacy materials. May } \\
\text { not be able to read prescription materials }\end{array}$ \\
\hline $45-60$ & $221(43.8 \%)$ & 7th to 8th Grade & $12-14$ & $\begin{array}{l}\text { Will struggle with most patient } \\
\text { education materials. Will not be } \\
\text { offended by low literacy materials }\end{array}$ \\
\hline $61-66$ & $284(56.2 \%)$ & 9th to 12 th Grade & $>14$ & $\begin{array}{l}\text { Will be able to read most patient education } \\
\text { materials }\end{array}$ \\
\hline
\end{tabular}

REALM, Rapid Estimate of Adult Literacy in Medicine. 
ARTICLE

Table 3 Sexual behaviour and reading ability

\begin{tabular}{|c|c|c|c|}
\hline \multirow[t]{2}{*}{ Question } & \multicolumn{3}{|l|}{ Cohort $(n(\%))$} \\
\hline & $\begin{array}{l}\text { Reading age } 12-14 \text { years } \\
(n=221)\end{array}$ & $\begin{array}{l}\text { Reading age }>14 \text { years } \\
(n=284)\end{array}$ & $\begin{array}{l}\text { Whole group } \\
(n=505)\end{array}$ \\
\hline \multicolumn{4}{|c|}{ What age were you when you first had sexual intercourse?*** } \\
\hline $14-15$ years & $128(57.9)$ & $118(41.6)$ & $246(48.7)$ \\
\hline $16-21$ years & $93(42.1)$ & $166(58.4)$ & $259(51.3)$ \\
\hline \multicolumn{4}{|c|}{ What method of contraception did you or your partner use on that occasion?* } \\
\hline None & $36(16.3)$ & $29(10.2)$ & $65(12.9)$ \\
\hline Condom/pill/both & $185(83.7)$ & $255(89.8)$ & $440(87.1)$ \\
\hline \multicolumn{4}{|c|}{ How many sexual partners have you had in the last 6 months?** } \\
\hline 0 or 1 & $179(81.0)$ & $272(90.5)$ & $436(86.3)$ \\
\hline$\geq 2$ & $42(19.0)$ & $27(9.5)$ & $69(13.7)$ \\
\hline
\end{tabular}

${ }^{*} p<0.05 . * * p<0.002 . * * * p<0.001$. The numbers in parentheses are percentage values.

mean score of $64.81(\mathrm{SD}=1.56)$. The two groups were compared on their sexual health knowledge and sexual behaviour.

\section{Sexual behaviour}

There was a small but significant difference $(t=3.4$, df $=$ $503, p<0.001)$ in the age of first sexual intercourse between the higher and lower literacy groups. Those in the lower literacy group were significantly more likely to have first sexual intercourse at a younger age (mean $=15.52$ years, $\mathrm{SD}=1.05)$ than the high literacy group (mean $=15.85$ years, $\mathrm{SD}=1.09$ ). This is confirmed by a Chi-square analysis $\left(\chi^{2}=13.33, \mathrm{df}=1, p<0.001\right)$ of the proportions in each group having first sexual intercourse before or after 16 years (Table 3 ). The lower literacy group were also significantly more likely $\left(\chi^{2}=4.095 ; \mathrm{df}=1, p<0.05\right)$ not to have used contraception on that occasion $(16.3 \%$ vs $10.2 \%)$. A higher proportion of the low literacy group had more than one sexual partner in the last 6 months $\left(\chi^{2}=9.5\right.$; $\mathrm{df}=1, p<0.002)$ There was no difference in the number of planned or unplanned pregnancies, previous use of emergency contraception, and number of sexual partners in the previous 4 weeks.

\section{Sexual knowledge}

Table 4 shows the responses of both literacy level groups to the sexual knowledge questions. Several significant differences between the two groups were found with regard to sexual knowledge. Women with lower functional health literacy were significantly less likely to know the fertile period within a women's menstrual cycle $\left(\chi^{2}=38.31, \mathrm{df}=1, p<0.001\right)$, significantly less likely to identify sexually transmitted infections (STIs) $\left(\chi^{2}=\right.$ 89.27 , df $=1, p<0.001$ ) and significantly less likely to know that STIs could be transmitted by giving oral sex $\left(\chi^{2}=30.98, \mathrm{df}=2, p<0.001\right)$, receiving oral $\operatorname{sex}\left(\chi^{2}=\right.$ 81.76 , $\mathrm{df}=2, p<0.001)$ and anal sex $\left(\chi^{2}=92.05\right.$, $\mathrm{df}=2$, $p<0.001)$.

Table 4 Sexual knowledge and reading ability

\begin{tabular}{|c|c|c|c|}
\hline \multirow[t]{2}{*}{ Question } & \multicolumn{3}{|l|}{ Cohort $(n(\%))$} \\
\hline & $\begin{array}{l}\text { Reading age } 12-14 \text { years } \\
(n=221)\end{array}$ & $\begin{array}{l}\text { Reading age }>14 \text { years } \\
(n=284)\end{array}$ & $\begin{array}{l}\text { Whole group } \\
(n=505)\end{array}$ \\
\hline \multicolumn{4}{|c|}{ At what time in a women's cycle is she most likely to get pregnant?* } \\
\hline The week after her period starts & $7(3.2)$ & $1 \quad(0.4)$ & 8 (1.6) \\
\hline The week after her period ends & $8(3.6)$ & $10(3.5)$ & $18 \quad(3.6)$ \\
\hline The week starting 2 weeks before her next period* & $136(61.5)$ & $243(85.6)$ & $379(75.0)$ \\
\hline The week before her next period & $14(6.3)$ & $14(4.9)$ & $28(5.5)$ \\
\hline Don't know* & $56(25.4)$ & $16(5.6)$ & $72(14.3)$ \\
\hline \multicolumn{4}{|l|}{ Which of these are STIs? } \\
\hline Chlamydia & $206(93.2)$ & $283(99.6)$ & $489(96.8)$ \\
\hline Syphilis* & $60(27.1)$ & $195(68.7)$ & $255(50.5)$ \\
\hline Gonorrhoea* & $153(69.2)$ & $251(88.4)$ & $404(80.0)$ \\
\hline Impetigo & $7(0.3)$ & $8(0.03)$ & $15 \quad(2.9)$ \\
\hline Thrush* & $120(54.3)$ & $78(27.5)$ & $198(39.2)$ \\
\hline Chlamydia, syphilis and gonorrhoea* & $52(10.3)$ & $187(65.8)$ & $239(47.3)$ \\
\hline \multicolumn{4}{|l|}{ What is meant by safer sexual behaviour? } \\
\hline Having fewer sexual partners & $48(21.6)$ & $60(21.1)$ & $108(21.4)$ \\
\hline Using condoms & $171(77.4)$ & $220(77.5)$ & $391(77.4)$ \\
\hline Anal sex & $0 \quad(0)$ & $0 \quad(0)$ & $0 \quad(0)$ \\
\hline Unprotected sex & $1 \quad(0.5)$ & $1(0.4)$ & $2(0.4)$ \\
\hline Don’t know & $1 \quad(0.5)$ & $3(1.0)$ & $4(0.8)$ \\
\hline \multicolumn{4}{|l|}{ Can you catch STIs by oral sex by you to your partner?* } \\
\hline Yes & $182(82.4)$ & $270(95.1)$ & $452(89.5)$ \\
\hline No & $6(2.7)$ & $9(3.1)$ & $15 \quad(3.0)$ \\
\hline Don't know & $33(14.9)$ & $5 \quad(1.8)$ & $38 \quad(7.5)$ \\
\hline \multicolumn{4}{|l|}{ Can you catch STIs by oral sex by partner to you?* } \\
\hline Yes & $115(52.0)$ & $249(87.7)$ & $364(72.1)$ \\
\hline No & $31(14.0)$ & $17(6.0)$ & $48(9.5)$ \\
\hline Don't know & 75 (33.9) & $18 \quad(6.3)$ & $9(18.4)$ \\
\hline \multicolumn{4}{|l|}{ Can you catch STIs by anal sex?* } \\
\hline Yes & $81(36.7)$ & $223(78.5)$ & $304(60.2)$ \\
\hline No & $25(11.3)$ & $7(2.5)$ & $32(6.3)$ \\
\hline Don't know & $115(52.0)$ & $54(19.0)$ & $169(33.5)$ \\
\hline
\end{tabular}

${ }^{*} p<0.001$. The numbers in parentheses are percentage values. STI, sexually transmitted infection. 
ARTICLE

Table 5 Sources of sexual health knowledge

\begin{tabular}{|c|c|c|c|}
\hline \multirow[t]{2}{*}{ Question } & \multicolumn{3}{|l|}{ Cohort $(n(\%))$} \\
\hline & $\begin{array}{l}\text { Reading age } 12-14 \text { years } \\
(n=221)\end{array}$ & $\begin{array}{l}\text { Reading age }>14 \text { years } \\
(n=284)\end{array}$ & $\begin{array}{l}\text { Whole group } \\
(n=505)\end{array}$ \\
\hline \multicolumn{4}{|l|}{ Where do you get your information about contraception? } \\
\hline School & $60(27.1)$ & $71(25.0)$ & $131(25.9)$ \\
\hline Friends & $62(28.0)$ & $60(21.1)$ & $122(24.2)$ \\
\hline Nurse & $42(19.0)$ & $69(24.1)$ & $111(22.0)$ \\
\hline Family & $34(15.4)$ & $41(14.4)$ & $75(14.8)$ \\
\hline General practitioner & $9(4.1)$ & $18(6.3)$ & $27(5.3)$ \\
\hline Magazines & $2(0.8)$ & $1(0.4)$ & $3(0.6)$ \\
\hline \multicolumn{4}{|c|}{$\begin{array}{l}\text { How would you prefer the clinic to give you information to go with what is } \\
\text { said in the clinic? }\end{array}$} \\
\hline Leaflet & $206(93.2)$ & $263(92.6)$ & $469(92.9)$ \\
\hline Video & $14(6.3)$ & $14 \quad(4.9)$ & $28 \quad(5.5)$ \\
\hline Cassette tape & $0 \quad(0)$ & (0) & $0 \quad(0)$ \\
\hline CD ROM & $0 \quad(0)$ & $0 \quad(0)$ & $0 \quad(0)$ \\
\hline Website & $1(0.5)$ & $7(2.5)$ & $8(1.6)$ \\
\hline E-mail & $0 \quad(0)$ & $0 \quad(0)$ & $0 \quad(0)$ \\
\hline \multicolumn{4}{|c|}{$\begin{array}{l}\text { Do you feel you know enough about the different methods of contraception or } \\
\text { would you like to know more?** }\end{array}$} \\
\hline Know enough, don't want to know any more & $42(19.0)$ & $103(36.3)$ & $145(28.7)$ \\
\hline Know quite a lot, but would like to know a bit more & $131(59.3)$ & $167(58.8)$ & $298(59.0)$ \\
\hline Know a little bit, would like to know a lot more & $48(21.7)$ & $14(4.9)$ & $62(12.3)$ \\
\hline Don’t know anything & $0 \quad(0)$ & $0 \quad(0)$ & $0 \quad(0)$ \\
\hline \multicolumn{4}{|l|}{ Do you read the family planning leaflets given to you? } \\
\hline Yes & $209(94.6)$ & $261(91.9)$ & $470(93.1)$ \\
\hline No & $6(2.7)$ & $9(3.2)$ & $15 \quad 3.0$ \\
\hline Never been given a leaflet & $6(2.7)$ & $14 \quad(4.9)$ & $20 \quad(4.0)$ \\
\hline \multicolumn{4}{|c|}{$\begin{array}{l}\text { Did you find the leaflet helped you feel knowledgeable about your method } \\
\text { of contraception?* }\end{array}$} \\
\hline Very helpful & $65(29.4)$ & $59(20.8)$ & $124(24.5)$ \\
\hline Helpful & $131(59.3)$ & $187(65.8)$ & $318(63.0)$ \\
\hline Neither helpful or unhelpful & $12(5.4)$ & $11(3.9)$ & $23(4.6)$ \\
\hline Not helpful & $3(1.4)$ & $6(2.1)$ & $9(1.8)$ \\
\hline Not at all helpful & $0 \quad(0)$ & $1 \quad(0.4)$ & $1 \quad(0.2)$ \\
\hline Not applicable/no response & $10(4.5)$ & $20 \quad(7.0)$ & $30 \quad(5.9)$ \\
\hline
\end{tabular}

${ }^{*} p<0.05 .{ }^{*} p<00.001$. The numbers in parentheses are percentage values.

Less than half the sample $(239,47.3 \%)$ was able to identify all three STIs on the list they were shown. There was no difference between the groups' knowledge on what constituted safer sexual behaviour.

\section{Sources of sexual health knowledge}

Respondents were asked about their sources of knowledge about contraception (Table 5). There were no significant differences in sources of knowledge or preference about what additional sources (e.g. leaflet, video, etc.) could be supplied or attitudes to leaflets between the two literacy groups. However, there was a significant difference in the provision of additional information $\left(\chi^{2}=41.44\right.$, $\mathrm{df}=2$, $p<0.001$ ), where a higher proportion of the low literacy group wished to know more about contraception. There was a small and only marginally significant difference between the groups as regards attitude towards the current leaflets (Mann-Whitney $U=284.33$, df $=503, p<0.05$ ), with the high literacy group finding them more helpful.

\section{Readability of currently available literature on reproductive health}

A total of 20 leaflets were tested for readability. Ten were obtained from family planning clinics in Glasgow and 10 were from the Ayrshire and Arran clinic. The Ayrshire leaflets were from the fpa (Family Planning Association) and the Glasgow leaflets were locally produced. FleschKincaid scores for the Glasgow leaflets ranged from 3.0 to 7.5 (reading ages 8-11 years) and the Ayrshire leaflets from 6.1 to 12 (reading ages $10-17$ years).

Mean SMOG scores were 8.7 (range, 7-10) for Greater Glasgow leaflets and 10.5 (range, 8-13) for Ayrshire and Arran leaflets. The mean score for all leaflets considered was 9.6 (reading age 13-14 years). The information sheet on the study given to clients had a SMOG score of 8 , equivalent to a reading age of 12 years.

As the leaflets within the Ayrshire and Arran area had higher readability scores than those within Glasgow, the sexual behaviours and knowledge among the lower literacy groups in each area were compared to determine any significant differences. No significant differences were found between the two groups.

\section{Discussion}

Some $20 \%$ of adults in the UK have low basic literacy skills. ${ }^{11,12}$ In practical terms this means that one in five people cannot locate the page reference for plumbers if given the alphabetical index of the Yellow Pages ${ }^{\mathrm{TM}}$ telephone directory. ${ }^{12}$ This is below the literacy skill expected of an 11year-old child. ${ }^{12}$ Risk factors strongly associated with low literacy skills are: ${ }^{11}$ leaving education aged 16 years or less, being on a low income and being in a manual social class group. Thus, a significant proportion of the population might be expected to encounter problems when using health services because of limited literacy skills. Interestingly, many people with low literacy do not perceive themselves to have a problem. ${ }^{10}$ For example, in Scotland, although 800000 adults appear to have low literacy skills, only 500000 assess their own skills as poor or moderate. ${ }^{11}$

Our findings are congruent with other studies that examined the readability levels of materials within the health care system. ${ }^{1,2,13}$ These studies suggest that there is a disparity between health materials and readers, and that those health care materials are written at a higher level than will be comprehensible to the general public.

The findings of the current study suggest that those clients within the sample who had a reading age of 12-14 years would have problems understanding some of the 
leaflets, and indeed 16/20 leaflets analysed fell into this category. The only leaflets of a level accessible to all participants came from the Glasgow clinics. Thus, Ayrshire clients in the lower literacy group would have difficulty in understanding all the leaflets used in Ayrshire. Despite the Ayrshire health literature being harder to read, there were no significant differences in sexual health knowledge between the lower literacy Ayrshire participants and the Glasgow lower literacy group. This suggests that family planning clinic attendees are not solely reliant on literature for acquiring knowledge about sexual health.

Various sources of sexual health knowledge were identified by respondents. The most frequently cited source was school, closely followed by friends. Other studies have shown that people with low literacy turn first to family and friends for information rather than to health experts. ${ }^{14}$

Most women preferred to receive information in leaflet form to supplement that supplied orally by clinic staff. Most respondents read the leaflets supplied by the clinics and most found them helpful or very helpful. Despite this, most women also said that they would like more information about methods of contraception. This suggests that either the leaflets are not comprehensive enough or are poorly understood. Low literacy skills will not be overcome simply by transferring text to a computer screen; creativity is needed to improve understanding with this medium (e.g. use of sound and pictures). People with low literacy skills frequently also have poor verbal skills, so this aspect of communication must also be handled with care and consideration.

\section{Limitations of the study}

Certain limitations should be taken into account when interpreting the findings of this study. It was necessary to use a literacy assessment tool, since self-reporting of reading ability is often inaccurate (i.e. people may deny having a problem or not recognise that they do). ${ }^{1}$ Neither can reading skills be accurately predicted from education level completed. ${ }^{1}$ The main advantage of REALM is the brief time required for administration compared with more comprehensive literacy assessment tools. REALM provides an estimate of patient reading ability, displays excellent concurrent validity with standardised reading tests and is a practical instrument for busy primary care settings. ${ }^{4}$ However, REALM may overestimate reading ability as it only estimates the ability to pronounce words correctly, not understanding of their meaning. ${ }^{1}$

None of the participants was found to have very low literacy skills, which is not what would be expected given the high levels of poor literacy skills in the general population. Eighty-five participants refused to take part in the study. Although there is no way of determining their individual reasons for this, it may have been because of poor literacy skills. ${ }^{1}$ People with low literacy skills are careful to conceal their poor reading skills, and when handed the information sheet explaining the study they may have been deterred from taking part. Some thought, therefore, should be given to alternative ways of approaching potential research participants other than relying on written information sheets.

The study may also have recruited a sample with a skewed level of literacy. Attendance at family planning clinics is influenced by the decision to seek care and there is an emphasis on individuals taking responsibility for their own well-being. These factors may be associated with higher literacy skills.

Low literacy is more prevalent in elderly populations, as skills are lost if they are not used regularly. ${ }^{11}$ Since family planning clinic users tend to be young, the prevalence of low literacy would be expected to be lower than the national prevalence. Gazmararian found a $10 \%$ low literacy rate in her USA family planning clinic population against a population rate of $26 \% .15$ She also estimated that a further $10 \%$ would probably have milder but significant reading problems. The low literacy group was more likely to have poor knowledge of fertility and contraception, and more likely to say that they wanted more information on these topics.

We have taken participants' response to the questions asked at face value. The reported age at first intercourse is in keeping with other surveys. ${ }^{16}$ The validity of responses to questions about age of first intercourse and use of contraception on that occasion may be affected by the desire to preserve self-image. However, since the reported use of contraception is much lower than reported in other surveys (e.g. NATSAL II ${ }^{16}$ ) this is unlikely to have been a factor. We are unable to tell if such an effect would differ between people with low and high literacy.

\section{Conclusions}

This study has identified reduced health literacy levels in some female family planning attendees and shows differences in sexual health behaviour and knowledge according to literacy level. Those individuals with lower literacy levels were significantly more likely to have been aged under 16 years at time of first sexual intercourse, and significantly less likely to know the most fertile time of the menstrual cycle, less likely to identify STIs and less likely to know that STIs can be transmitted through oral and anal sex. This group were found to want more information on contraception and to find leaflets less helpful.

Currently available family planning literature is too hard to read for many clients. Despite this, there were no significant differences in sexual health knowledge between those individuals who accessed only difficult material from those who accessed easier-to-read literature. Respondents in both literacy categories reported a wide range of sexual health knowledge sources.

Health literacy is related to sexual behaviour and knowledge. Low literacy is common. Written information should be prepared with this fact in mind and other ways of tackling poor sexual health knowledge and behaviour considered.

\section{Acknowledgement}

This study was funded by the NHS Prioritisation of Needs Programme Social Determinants and Intervention for Health Programme. The authors are grateful to Karen Bell for assistance in getting the project established and to Angela Hisset, Librarian, for her help with the literature search.

\section{Statements on funding and competing interests}

Funding. None identified.

Competing interests. None identified.

References

1 Baker D. The healthcare experience of patients with low literacy. Arch Fam Med 1996; 5: 329-334.

2 Weiss BD, Coyne C. Communicating with patients who cannot read. N Engl J Med 1997; 337: 272-274.

3 Brez SM, Taylor M. Assessing literacy for patient teaching: perspectives of adults with low literacy skills. J Adv Nurs 1997; 25: 1040-1047.

4 Parker RM, Williams MV, Baker DW, Nurss JR. Literacy and contraception: exploring the link. Obstet Gynecol 1996; 88(3 Suppl.): 72S-77S

5 Scottish Executive. Adult Literacy Skills in the Labour Market: A Literature Review. Edinburgh, UK: Scottish Executive, 2001. http://www.scotland.gov.uk/library3/lifelong/alrlr-00.asp [Accessed 30 May 2006]

6 Analysis of National Survey of Sexual Attitudes and Lifestyles (NATSAL) 2000 data for Scotland on the Health Education Board for Scotland website. http://www.hebs.scot.nhs.uk/topics/topiccontents. cfm?TxtTCode $=1437 \&$ TA $=$ topictitles \&newsnav $=1 \&$ topic $=$ hiv $/$ sexual [Accessed 30 May 2006]. 
7 Davis TC, Michielutte R, Askov EN, Williams MV, Weiss BD. Practical assessment of adult literacy in health care. Health Educ Behav 1998; 25: 613-624.

8 McLaughlin GH. SMOG grading - a new readability formula. Journal of Reading 1969; 12: 639-646.

9 Kincaid JP, Fishburne RP, Rogers RL, Chissom BS. Derivation of New Readability Formulas (Automated, Readability Index, Fog Count, and Flesch Reading Ease Formula) for Navy Enlisted Personnel. Research Branch Report 8-75. Memphis, TN: Naval Air Station, 1975.

10 Davis T, Crouch M, Long S, Green K. Rapid Estimate of Adult Literacy in Medicine (REALM). Undated instruction book that accompanies the REALM kit. Shreveport, LA: Health Sciences Center, Lousiana State University.

11 Scottish Executive. Adult Literacy and Numeracy in Scotland. Edinburgh, UK: Scottish Executive, July 2001. http://www.scotland. gov.uk/library3/lifelong/alan-00.asp [Accessed 30 May 2006].

12 Improving Literacy and Numeracy: A Fresh Start. The report of the working group chaired by Sir Claus Moser. London, UK: Department for Education and Employment, March 1999. http://www.lifelong learning.co.uk/mosergroup [Accessed 30 May 2006].

13 Wilson R, Kenny T, Clark J, Moseley D, Newton L, Newton D, et al. PILs Project Summary Report: Ensuring the Readability, Understandability and Efficacy of Patient Information Leaflets (PRODIGY Publication No. 30). Newcastle-upon-Tyne, UK: Sowerby Centre for Health Informatics, School of Social Sciences, University of Newcastle-upon-Tyne, 1988.

14 Rudd RE, Moeykens BA, Colton TC. Health and literacy - a review of public health literature. In: Comings J, Garner B, Smith C (eds), Annual Review of Adult Learning and Literacy, vol. 1. San Francisco, CA: Jossey-Bass, 2000; 158-199.

15 Gazmararian JA, Parker RM, Baker DW. Reading skills and family planning knowledge and practices in a low-income managed care population. Obstet Gynecol 1999; 93: 239-244.

16 Wellings K, Nanchahal K, Macdowall W, et al. Sexual behaviour in Britain: early sexual experience. Lancet 2001; 358: 1843-1850.

\section{Readers' contributions invited for a new Journal section entitled 'A Better Way of Working'}

Launching in the January 2007 issue, the Journal proposes publishing a new section entitled 'A Better Way of Working', the purpose of which is to disseminate service delivery suggestions likely to be of interest and relevance to the Journal's readership.

Readers are invited to submit suggestions based on their own personal experience for consideration by the Journal Editor. Contributions should not exceed 250-500 words and should be written in a standardised format responding to the following four questions: Why was change needed? How did you go about implementing change? What advice would you give to others who might be considering a similar course of action? How did you show that the change had occurred?

All contributions should be submitted via the Journal's online submission system at http://jfprhc.allentrack.net or alternatively they may be e-mailed to the Journal Editorial Office at journal@ffprhc.org.uk.

\section{vasectomy services}

\section{Over 100,000 men have chosen us...}

making Marie Stopes International the country's most experienced vasectomy provider. With 20 centres nationwide we are able to offer a quick, reliable and straightforward service with no waiting lists.

For men who want the convenience of counselling, assessment and procedure on one day we offer a same day service. Our "non scalpel vasectomy technique" takes just a few minutes with no stitches and we provide all post operative aftercare and semen testing.

If you or your patient would like more information, simply call the number below and we will send further details.

Call us on 08451203644 - 24 hours or visit www.mariestopes.org.uk

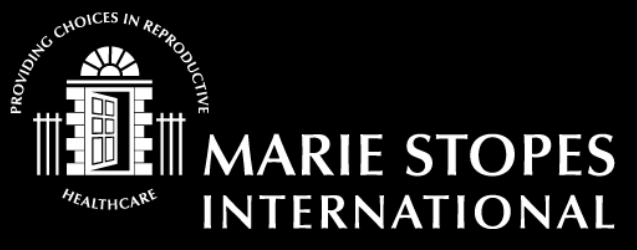

